\title{
A Conversation Analytical Study of Telephone Conversation Openings between Native and Nonnative Speakers
}

\author{
Carmen Taleghani-Nikazm \\ The University of Kansas \\ Department of Germanic Languages and Literatures \\ 2080 Wescoe Hall \\ Lawrence, KS 66045 \\ U.S.A.
}

Keywords: Conversation Analysis, telephone conversation openings, native-nonnative speaker interaction, pragmatic transfer, conversational routines

\begin{abstract}
The purpose of this paper is twofold: First, it contrasts "ritual routines" in telephone conversation openings in Iran and Germany. Specifically, it focuses on the interactional organization of the ritual "how are you" sequence in both cultures. Further, it illustrates how the ritual "how are you" sequence is expanded in the Iranian telephone conversation openings: in opening a conversation on the phone, after inquiring about one another's wellbeing the Iranian co-participants move one step further and inquire about the well-being of their respective families. Unlike Iranian telephone conversation openings, however, German telephone conversation openings often do not include the ritual "how are you". When German co-participants do perform a set of a "how are you" sequences, they are not reciprocated. The first part of the "how are you" sequence frequently functions as a topic elicitation. In other words, the response to an inquiry about the co-participant's well-being is usually topicalized.

The second part of this paper presents some transfer of the culture specific differences in the telephone conversation opening routines in conversations between Iranian nonnative speakers of German and German native speakers. Specifically, it illustrates how German native speakers understand and orient to the ritual inquiries about themselves and their family as topic elicitation.
\end{abstract}

\section{Introduction}

Gumperz (1982:166) notes that while speech activities exist in all cultures, there might be differences in the ways particular activities are carried out and signaled. This paper uses one particular speech activity, viz. telephone openings to conduct a cross-cultural comparison and analysis of human interaction. Using Conversation Analysis (CA) as the methodology, this study contrasts and illustrates the cultural differences in the format and interactional routines of opening conversations on the telephone in the Iranian and German speech communities. The focus of this analysis will be the speech after the exchanges of greetings in the telephone conversation opening. Further, this paper will discuss telephone conversation openings in Germany that are between native speakers of German and Iranian nonnative speakers of German. Specifically, it will illustrate how the cultural differences in 
the ritual "how are you" within telephone conversation openings may interfere with native and nonnative speaker's intentions and expectations when talking on the phone.

\subsection{Telephone conversation openings}

In general, the beginning of conversations has received much attention in the fields of sociolinguistics, pragmatics, and conversation analysis (Schegloff and Sacks, 1973; Schegloff, 1979; Coulmas, 1981; Laver, 1981; Gumperz, 1982; Schegloff, 1986; Coupland et al., 1992; Hopper, 1992; Pavlidou, 1994). One context in which the beginning of conversations has been extensively studied is telephone conversations (Schegloff and Sacks, 1973; Godard, 1977; Schegloff, 1979; Schegloff, 1986; Sifianou, 1989; Lindström, 1990; Houtkoop-Steenstra, 1991; Hopper, 1992; Pavlidou, 1994; Taleghani-Nikazm, forthcoming). The study of conversation openings, particularly on the telephone, has become prominent for their following particular reasons:

a) Openings are interactionally compact and brief (Schegloff, 1986: 112).

b) Generally, at the beginning of a conversation, participants may utilize conversational strategies or "routines" to negotiate interpersonal relationships (Gumperz, 1982:142;

Schegloff, 1986: 113). This also counts for the beginnings of conversations on the telephone, as co-participants have resources available to them to manage identification and recognition of one another.

c) Schegloff $(1972,1979,1986)$ describes telephone conversation openings in American English in terms of an ordered set of four core opening sequences: (1) the summons-answer sequence (the phone ring and hello); (2) the identification-recognition sequence (i.e. partners display each other's recognition of the other) (for example, hello Clara?/yeh); (3) the exchange of greeting tokens (hi/hi), and (4) the how are you sequence (how are you/I'm awright. how are you) (1986:115). Accomplishing these tasks or "routines" is the focus of the first utterances in telephone conversation openings.

d) Another important feature of telephone conversation openings is that they have a "perfunctory" character (Schegloff, 1986:113). In other words, in opening a telephone conversation, participants go through these routines in a rather automated manner.

e) Further, one interactional organization feature of telephone conversation openings is that they provide a position that is described by Schegloff (1986: 117) as the "first topic". According to Schegloff (1986:117), after identification and recognition are achieved and a set of "how are yous" (if relevant) are exchanged, the caller usually uses the "anchor position" to introduce the "first topic" or the "reason for the call”. However, as Schegloff (1986: 117) notes, this is not the only possible position for the introduction of the first topic. In fact, there are possibilities for co-participants (the caller and the answerer) to preempt the introduction of the first topic. Therefore, "routine" openings need to be understood as "achievements" going through possibilities for preemptive first topic, rather than a “mechanical or automated playing out of pre-scripted routines”(Schegloff, 1986: 117).

\subsection{Cross-cultural studies on telephone conversation openings}


Some cross-cultural studies on telephone conversation openings in various speech communities (France, Greece, the Netherlands, Sweden, and Taiwan) have addressed the question of what is universal and what is culturally specific in such openings (Godard, 1977; Sifianou, 1989; Houtkoop-Steenstra, 1991; Lindström, 1994; Pavlidou 1994; Hopper and Chen, 1996). Some of these studies use the telephone opening sequences in American English described by Schegloff $(1972,1979,1986)$ as a template in order to explore how telephone conversation openings in other cultures are carried out (Houtkoop-Steenstra, 1991; Lindström, 1994; Pavlidou 1994; Hopper and Chen, 1996). Their analysis illustrates that although there are similarities in the opening sequences of telephone conversation, some cultural variation exist as well.

Godard (1977) explored the organization of telephone openings in French and suggests that some differences exist between summons-answer sequences in French versus American telephone openings. According to Godard, Americans interpret the answer to summons as an indication that the channel of communication is open; the French see it as an indication of the answerer's availability to be interrupted in the middle of what s/he was doing, not of her or his availability as a partner in the conversation. French callers thus provide an apology in the opening sequence.

In an investigation of Greek telephone openings, Sifianou (1989) found that there is a greater variety of linguistic options for answering the phone in Greek. In choosing a particular response type, Greeks can develop a personal style in answering the telephone. Thus, the answer to a summons may provide the caller with resources for identifying the answerer.

Houtkoop-Steenstra (1991) found that in Dutch telephone openings, Dutch speakers overwhelmingly self-identify by name in answering the phone. The caller in the subsequent turn also overwhelmingly self-identifies. Furthermore, the callers use a voice sample alone only if the caller is the spouse or a close relative of the person called. In doing so, the callers display intimacy. Houtkoop-Steenstra suggests that in Dutch society not self-identifying in answering the home telephone is considered impolite.

In her study of Swedish telephone conversation openings, Lindström (1994) describes how Swedes use a variety of responses when answering the phone. According to Lindström, the most common answer to summons in the Swedish data is self-identification followed by a phone number. Swedes self-identify by first and/or last name, greeting and selfidentification, station identification (i.e. phone number) and "hello". In Swedish telephone conversation openings, greetings are closely linked to the identification-recognition issue.

Pavlidou (1994) compared Greek and German telephone conversation openings, in particular the utterances occurring between summons-answer sequence and the first topic. Her study suggests that Greeks and Germans use phatic utterances ("how are yous") in different ways. Phatic utterances in Greek telephone conversation serve the purpose of enhancing the interpersonal relationship aspect of communication, whereas Germans seem to use phatic utterances to reduce a face threat that is connected with the reason for calling.

Hopper and Chen (1996) investigated telephone conversation openings in Taiwan. They explain that summons/answer, identification/recognition, and greeting sequences in telephone conversation in Taiwan seem to be similar to the American English, however, there seems to be some cultural variation in the greeting. In general, Hopper and Chen 
suggest that speakers in Taiwan use three distinctive greeting tokes and relative formality of address terms for family members. In doing so, speakers display their orientation to their interpersonal relationship.

The preceding overview suggests that, speakers in the studied cultures go through the telephone opening sequences described by Schegloff (1986) and that there are some cultural variations. The discussion will now turn to telephone openings in Iran and Germany. I will first briefly describe the source of my data. I will then use examples from my database to illustrate a number of Persian and German telephone opening behaviors.

\section{Data and transcription notation}

The research presented in this paper is based on a data corpus of 87 audio-taped telephone calls in Iran, 56 audio-taped German telephone calls ${ }^{1}$, and 45 audio-taped telephone calls between native speakers of German and Iranian nonnative speakers of German in Germany. All calls were made by middle-class Iranians and Germans, ranging in age between 25 and 60 years old. The telephone calls include conversations between relatives and friends. Seven persons in Iran, 5 native speakers of German in Germany, 4 native speakers of German living in the USA, and 5 Iranian nonnative speakers of German living in Germany were asked to audio-tape telephone calls initiated by themselves from their home, and telephone calls they received at home. Telephone calls were audio-taped during 1995, 1996, 1999, and 2000. All telephone call openings of the collected data were transcribed according to the transcription notation developed by Gail Jefferson (1984: ix-xvi) for conversation analysis (see appendix). In the transcripts, the top line is the original talk. The English translation is provided at the bottom of the original talk in italics.

\section{Telephone conversation openings in Iran}

The analysis of telephone calls in Iran suggests that similar to the sequential organization of telephone openings in American English, Iranians ordinarily go through the four opening sequences (summons/answer; identification/recognition; greetings, and an exchange of "how are yous"). However, there are some cross-cultural differences in the ways these actions are carried out. My Iranian data suggest that there is a cultural variation in the number of occurrences of the "how are yous" in telephone conversation openings². Beeman (1986: 181) and Moosavie (1986: 72) note that in the Iranian culture, it is important when people meet each other to spend some time in what is called saalamo ahvaalporsi. That is, an exchange of polite phrases which are mainly inquiries about the health and wellbeing of each other and of their respective families. This interactional behavior was also observed in my Iranian telephone conversation openings: Frequently, Iranian co-participants not only inquire about each other's well-being but also about their respective family's wellbeing. In other words, compared to "how are you" sequence in American English telephone

1 I would like to thank Andrea Golato for making 12 of these openings available.

${ }^{2}$ As mentioned earlier in this paper, the focus of this paper is on the "how are you" sequences in the telephone conversation openings in Iran. For more detailed analysis of the summons-answer, identification-recognition, and exchange of greetings sequences see Taleghani-Nikazm (forthcoming). 
openings, Iranian "how are you" sequence seems to be more elaborate ${ }^{3}$. Similar to the inquiry about each other's well-being, this is practiced in a rather routinized fashion.

Regularly, these ritual exchanges are performed before getting to talk about the reason for the call. This is illustrated in the following telephone conversation opening between two relatives in Iran. Said calls his brother-in-law Ali. Note that both co-participants inquire about the well-being of their families after asking about each other's state of health (lines 17). Ali asks how Said's wife (Zari) and daughter (Nasrin) are (lines 9 and 11). After responding to Ali, Said inquires about Ali's wife (Fariba) and son's (Amir) state of health (lines 12 and 18). The exchanges of "how are yous" and are marked with an arrow.

(1)

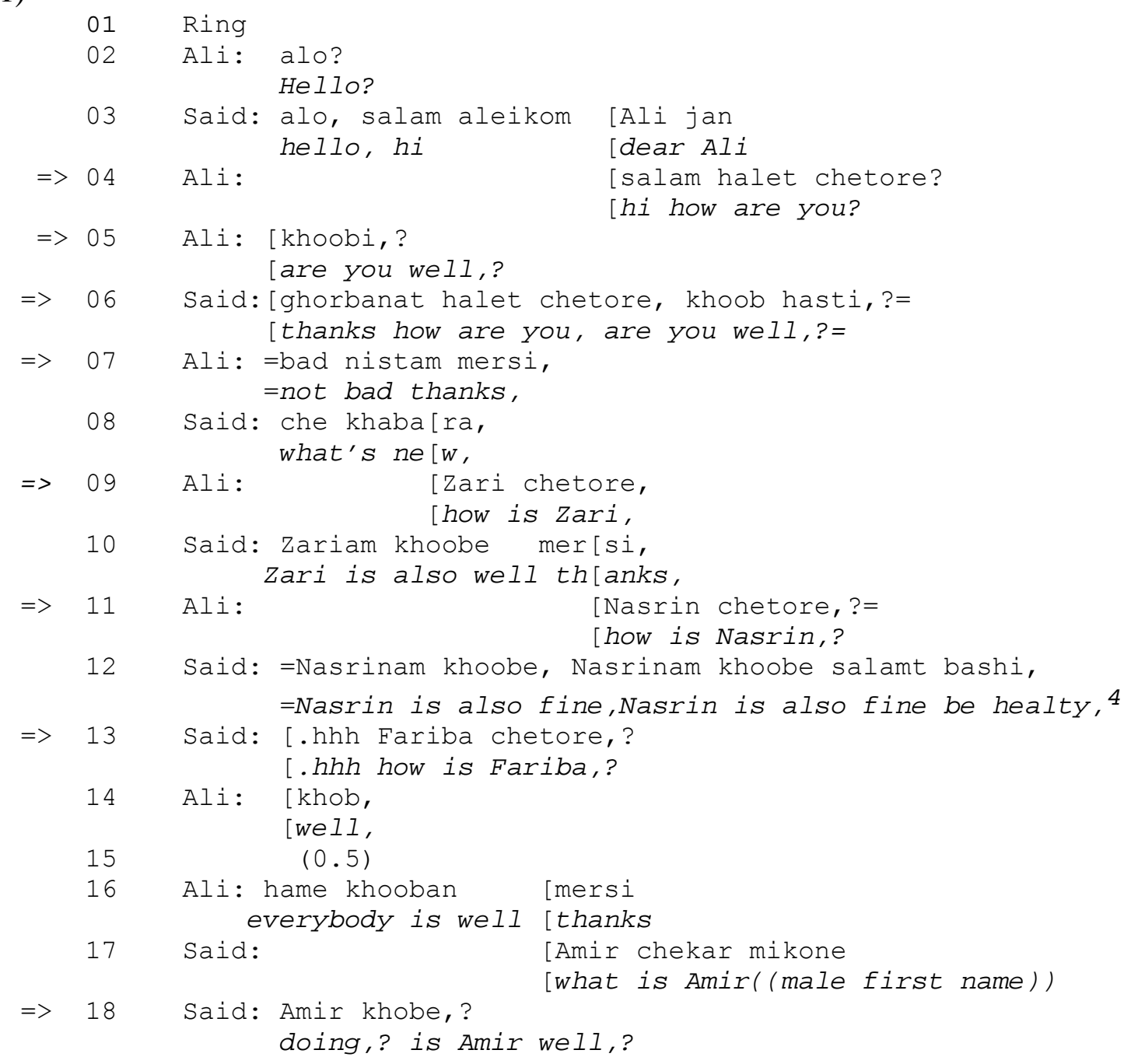

3 One of the anonymous reviewer made an interesting point about "why should English be the benchmark?" when analyzing interactional organization in other cultures. I agree with the reviewer and tried to employ wording in my analysis that would give equal status to the languages under study in this paper.

4 The idiomatic expression salamat bashi (be healthy) is frequently used as a response to the ritual inquiry of "how are you" in Persian. By using salamt bashi as a response to the inquiry, speakers wish their coparticipants "health". 


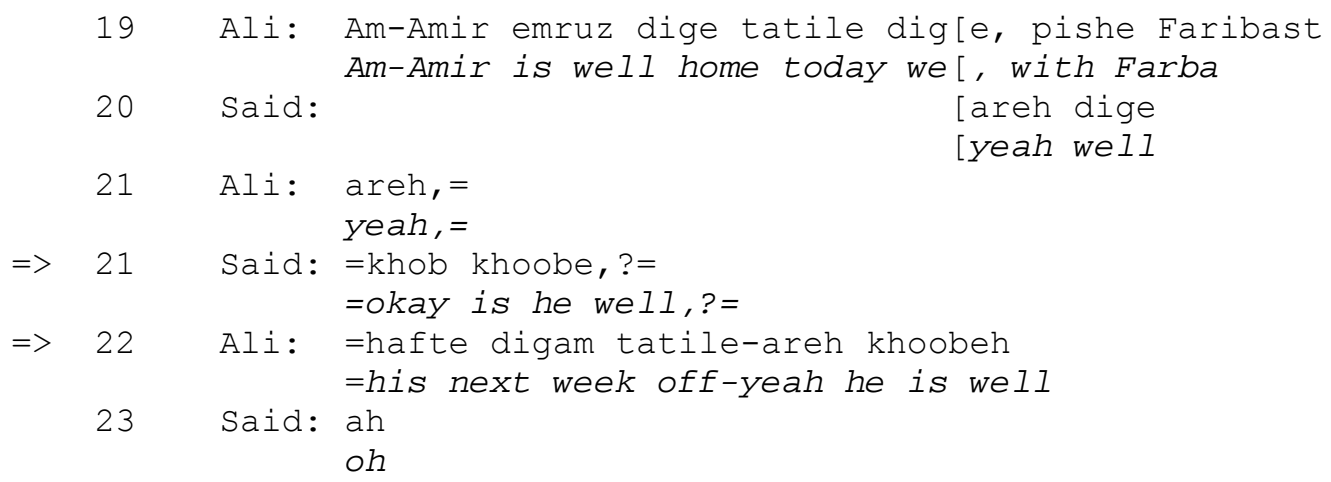

After identification and recognition are achieved, Ali utters the first ritual inquiries halet chetore? (how are you?) and khoobi,? (are you well?) (lines 4 and 5). Frequently, in my Iranian telephone conversation data, the co-participant's first part of the "how are you" sequence consists of two ritual inquiries, viz. a variation of halet chetore? and khoobi?. Both phrases are inquiries about the well-being of the co-participant. Khoobi or a similar variation usually follows halet chetore?. I did not find any other order of occurrence of the two ritual inquiries. The double inquiry usually either receives a single response as a second part, ghorbanat (thanks) or ghorbanat mersi (thank you, thanks).

After going through the "how are yous" the first topic position is relevant. In line 8, Said does topic elicitation by producing che khabara (what's new?) (line 8). This is an opportunity for the answerer (Ali) to talk about what's "talkable"5. However, the answerer (Ali) chooses to inquire about the well-being of the caller's (Said's) wife (line 9). Gumperz (1982: 131) notes that linguistic forms in a conversation may function as what he describes as "contextualization cues" by which "speakers signal and listeners interpret what the activity is”. In the above data segment, Ali's (answerer) initial inquiry about the caller's family member's well-being is understood by the caller as the "how is the family" activity. In other words, the answerer's ritual inquiries about the well-being of the caller's family create constraints on the part of the caller to also make similar inquiries about the answerer's family members' states. Furthermore, the inquiries about the spouses themselves create constraints on inquiries about the children's well-being.

In sum, in the context of telephone conversation openings, Iranian co-participants often interpret and understand the initial inquiry of their spouse's well-being as reciprocal inquiries about each others' families. Once initiated, these inquiries occur in a rather routinized manner and often in overlap with their previous turn (for example, lines 09, 10 and 11). When opening a conversation on the phone, Iranian speakers understand and orient to

5 The sequential position of che khabara (what's new) in this and similar data segments is very interesting. It seems that the caller (Said) has no intention of talking about the reason for the call, since this would be the position to introduce it. Thus the phrase che khabara seems to be used as a way to give the answerer the opportunity to introduce the first topic. Obviously, the interactional achievement of this phrase needs further indepth analysis. 
this particular routine because of the socio-cultural knowledge of the activity they share. After accomplishing this task, co-participants talk about the reason for the call ${ }^{6}$.

The routine of exchanges of "how is the family" between the caller and the answerer may also occur even if the caller's intention is to speak to someone other than the answerer. The following data excerpt exemplifies such a routine. Mamad, the caller, calls Mariam's house to talk to her husband. After an exchange of inquiries about one another's well-being, the answerer asks about the well-being of the caller's wife and children (lines 12 and 13).

(2)

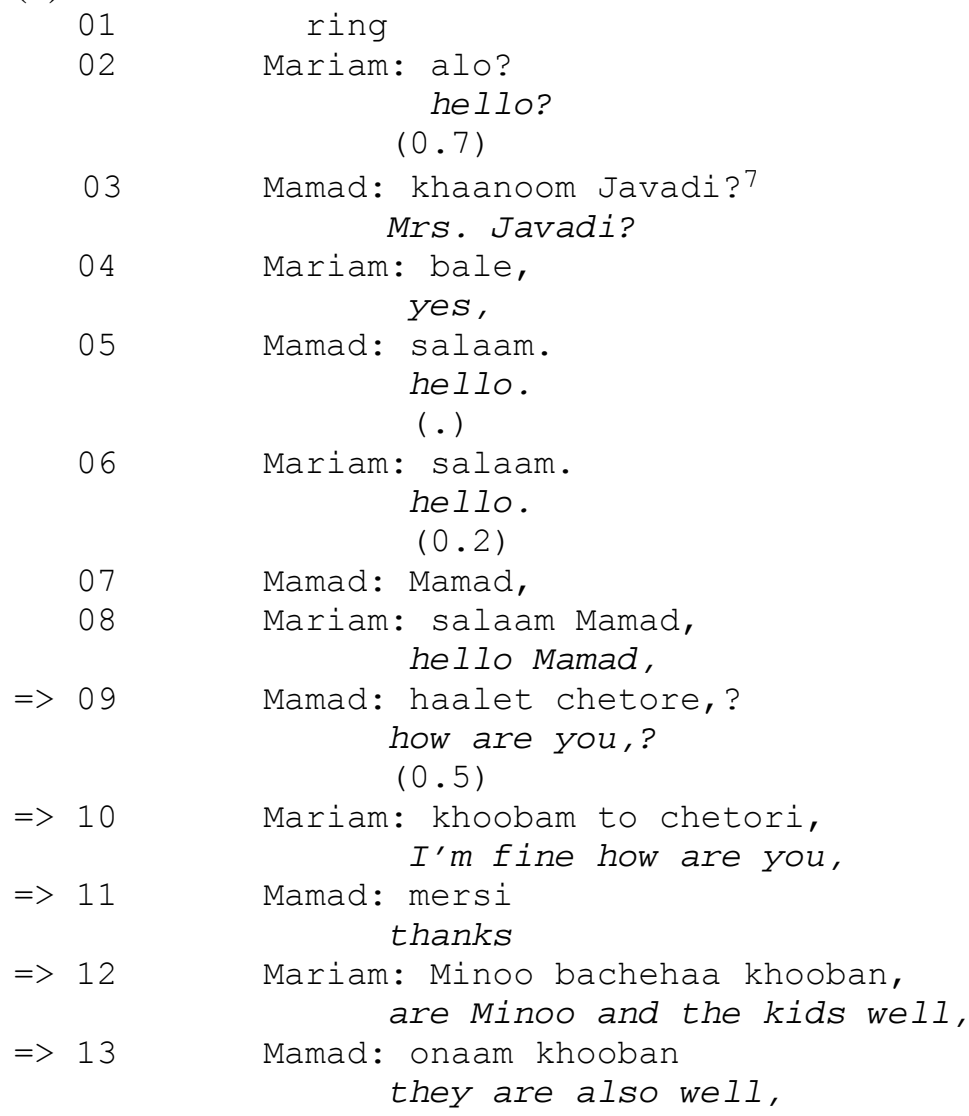

6 One of the referees recommended considering the notion of "phatic communion". I decided to exclude this notion from my analysis since "phatic communion" is described by Malinowski (1946: 313) as "language used in free, aimless, social intercourse". A language that "does not function here as a means of transmission of thought.” I do not see the numerous exchanges of inquiries about one's family well-being as first of all "aimless" and secondly "free". Speakers carry out these routines to achieve a specific position in the conversation on the telephone, namely the "first topic" (Schegloff, 1986: 117). In other words, they are performed in a very specific activity, namely telephone conversation openings with a very specific goal, in order to get to talk about the reason for the call. I have found these routines not only in telephone conversations in which parties called only for social and interpersonal reasons, but also in conversations in which parties had specific reason for the call.

7 Iranian callers in their first turn usually produce the presumed or intended recipient's last name preceded by an address term with interrogative intonation, thus asking for confirmation of whether they dialed the right number when they have not recognized the recipient by his or her voice sample (Taleghani-Nikazm, forthcoming). 
Similar to the previous example, after identification and recognition are achieved and a set of ritual "how are yous" are exchanged (lines 9-11), the answerer (Mariam) inquires about the well-being of the caller's (Mamad's) family (line 12). Note that Mamad does not inquire about Mariam's family: Mamad called to talk to Mariam's husband, thus the inquiry about her husband's well-being would not be relevant, since he will be talking to him (if he is available).

Schegloff (1986: 118-119) notes that in American English co-participants orient to multiple or to few rings of the phone in that the delayed or quick answering of the phone can develop into a topic. Frequently, following a delayed answering of the telephone, the caller inquires about the reason for the delay, which itself may then develop into a topic. In my Iranian telephone conversation opening data corpus, co-participants also orient to the delayed or quick answering of the telephone, and it is topicalized. However, co-participants first go through the ritual "how are yous" before talking about the delay. Unlike the previous examples of Iranian telephone conversation openings, during such an opening (with delayed answering), co-participants do not inquire about the well-being of each other's family. In other words, co-participant go through the minimum of the ritual inquiries, i.e. inquiring about each other's health, before talking about the reason for the delay in answering the telephone. The next data excerpt (3) illustrates such a telephone conversation opening. This is a telephone conversation between two relatives (a sister-in-law and mother-in-law) in Iran. Nazi had already called Minu and let the phone rang for a long time without there being an answer. Nazi immediately tried again to reach Minu. After Nazi greets Minu and selfidentifies (line 3), Minu greets her back and produces the first part of the "how are you" sequence by saying chetori,? (how are you) (line 4). In line 5, Nazi thanks Minu in response (second part of the "how are you") and inquires about Minu's health, shomaa khoobin,? (are you well?) (line 5). However, instead of giving Nazi a response, Minu asks her che khabar,? (what's up) (line 6). Nazi treats this as an inquiry about her well-being and responds to it accordingly (line 7) ${ }^{8}$. Note that Nazi talks about the delay in answering the phone after the ritual "how are yous" and at a position in which the introduction of first topic is relevant (lines 9 and 10).

(3)

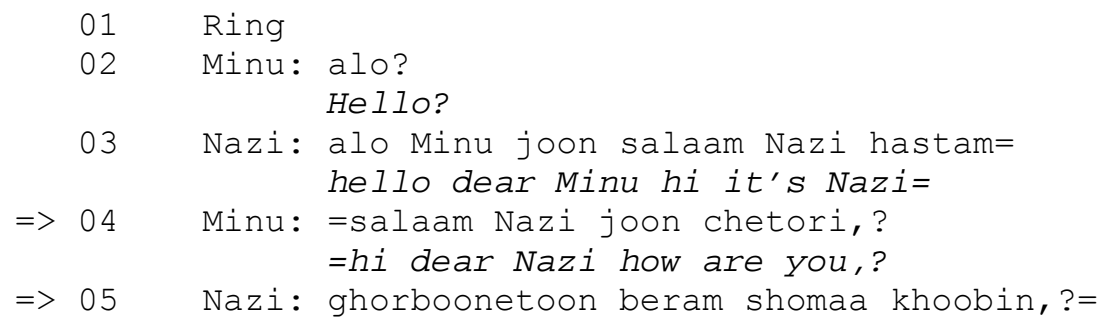

8 The interactional organization of the phrase che khabar? (what's up?) in Iranian telephone conversation openings needs more detail research. 


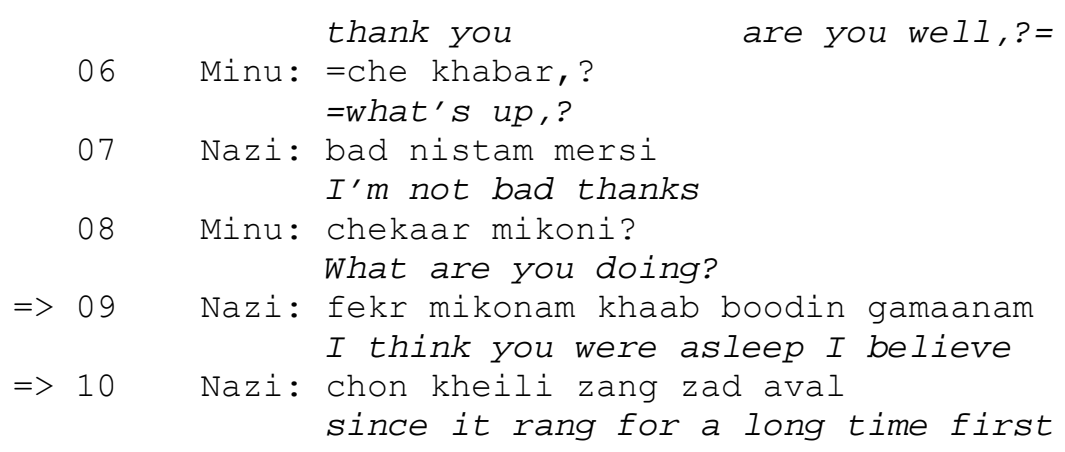

The ritual inquiries about the family members may also be excluded when the telephone conversation is between husband and wife. The next example of an Iranian telephone conversation opening illustrates a conversation between husband (Ali) and wife (Minu). Ali calls home to check with Minu on whether their son (Reza) has already brought the jewelry home (line 12). Note that Ali produces the first part of the "how are you" sequence before his talking about the reason for the call (line 10). Minu responds to Ali's first part of the "how are you" and also inquires about his well-being (line 11). However, instead of a response, Ali introduces the reason for the call. The second part of the second ritual "how are you" sequence is never produced. The conversation continues in that Minu answers Ali's question, whereupon they close the phone conversation.

(4)



Coulmas (1979: 240) notes that members in a society frequently perform "routine formulae" in an "automated" and "predictable" manner in specific standardized situations ${ }^{10}$. These

\footnotetext{
9 The pauses at the beginning of this telephone conversation are due to a bad connection, which can happen quite often in Iran.
} 
exchanges of routine formulae of ritual inquiries about one another's well-being, such as those which are performed in opening encounters on the telephone in Iran, are highly predictable in the course of interaction. Furthermore, Iranian co-participants, as members of the same "category" (Sacks, 164-65/1992: 40), Iranian culture, and sharing "common knowledge” (Sacks, 164-65/1992: 69) about telephone conversation routines in Iran, are aware of these routines and orient to them, i.e. they inquire about each other's well-being and their respective family's before getting to talk about the reason for the call.

\section{Telephone conversation openings in Germany}

In the following section, I will contrast the format and interactional organization of telephone conversation openings in Germany with telephone conversation openings in Iran. The analysis of telephone conversation openings in Germany ${ }^{11}$ suggests that, unlike the Iranian data corpus, the "how are you" sequence does not frequently occur in conversation between friends and relatives in Germany. A ritual "how are you" sequence may occur, however it is not reciprocal. In such conversations on the phone, the response to the first part of the "how are you" frequently develops into a topic.

The following data excerpt (5) illustrates a telephone conversation opening between two friends in Germany. Note that there is no exchange of the ritual "how are you" sequence. Sabine calls Martin to give him directions to the place where they want to meet later that day. Martin has been waiting for Sabine's call. After displaying his recognition of the caller ( ja? 'yeah') and returning Sabine's greeting by saying servus (hi) Martin expresses how glad he is that she called (gut dass du anrufst) (line 4) and talks about how he tried to find a sheet with directions.... (not included in the transcript).

(5)

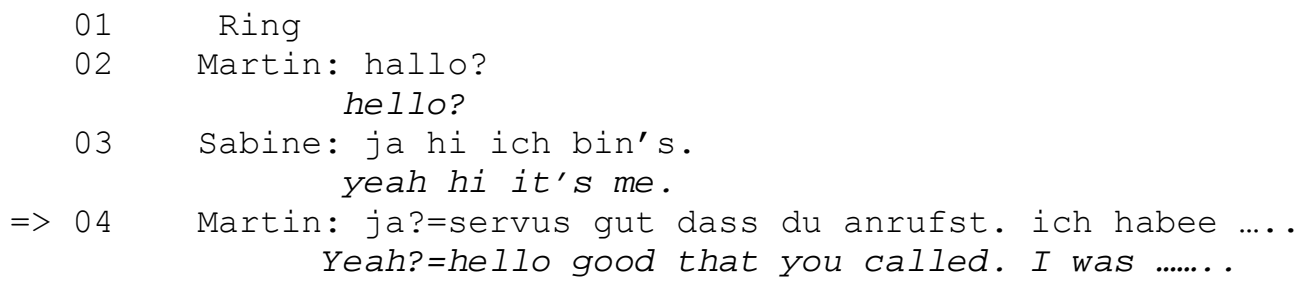

After the identification and recognition are achieved and a set of greetings are exchanged, coparticipants may introduce the first topic. This can be introduced either by the caller or by the answerer. This is illustrated in the following example (6). This is a conversation between two siblings, Dina and Karin. Dina calls her sister in Germany from America. During her previous phone conversation, Dina told her sister about preparing pumpkin for Thanksgiving. Karen introduces the first topic where she talks about how Dina inspired her to cook pumpkin (line 6-9). Note that similar to the previous example, no "how are you" sequence occurs.

10 In his comparative study of formulaic expressions, Coulmas (1979) gives examples from several cultures such as German, Greek, English and Japanese.

11 For other contrastive studies on German telephone conversation openings see Liefländer-Koistinen and Neuendorf (1991) for German-Finnish and Pavlidou (1994) for German-Greek. 
(6)

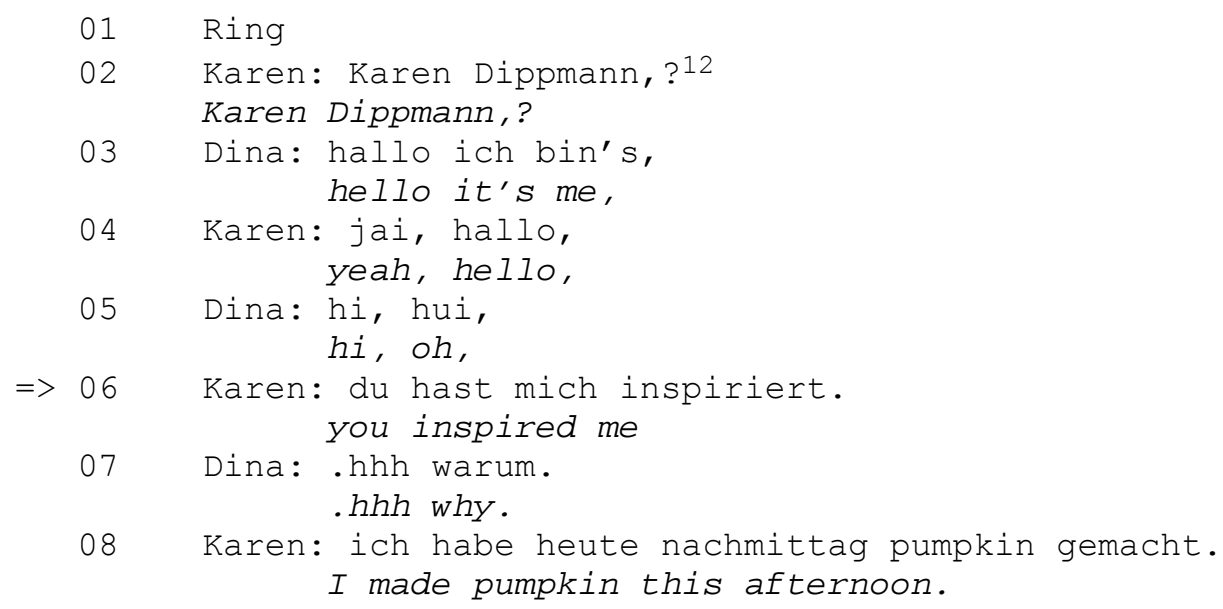

In my German telephone conversation data, various situations such as the number of rings (multiple or a few), or the quality of the answerer's voice may invoke a variety of motives and inferences that the caller may draw (Schegloff 1986: 119). In such cases, the caller usually inquires about the situation that is then topicalized. This occurs frequently right after identification and recognition are achieved and greetings are exchanged. Again, no ritual "how are you" sequences occur. The next data excerpt (7) is an example of such a telephone conversation opening. This is a phone conversation between two friends, Carlo and Jens. Jens is concerned that he might have woken up his friend since it is quite late (line 5).

(7)



In the majority samples in my collection of German telephone conversation openings (46) co-participants do not go through the ritual "how are yous". However, it seems that a "how

12 Frequently, Germans may answer the phone ring by self-identification. This may include the answerer's first name and last name or only the last name with rising intonation. For further analysis of the summonsanswer sequence in German telephone conversation openings see Pavlidou (1994: 494). 
are you" sequence does occur in telephone conversations between co-participants who have not talked to each other for some time (8 examples).

The ritual "how are you" sequence may also occur in a conversation between friends. Usually in American English, after a first inquiry receives an answer, a "reciprocal" inquiry by the recipient of the first is relevant (Schegloff, 1986: 130). However, unlike the ritual "how are you" sequences in the Iranian telephone conversation openings, the "how are you" sequence in the German telephone conversation opening is frequently not reciprocated. In other words, the receiver of the first part of the "how are you" sequence does not inquire about his or her co-participant's well-being. The response to the initial "how are you" is topicalized. This is illustrated in the next data excerpt (9). Max is on a student exchange program in America (at the time of the phone conversation) and calls his friend, Jan, in Germany. After Jan expresses his surprise (line 8) and Max expresses his difficulty reaching Jan (line 9), Jan produces the first part of the ritual "how are you" by saying wie geht's? (how are you?) (line 10). Max does not produce the second part of the "how are you" sequence and instead continues talking about how often he had tried to reach Jan and asks him whether he goes home every weekend (lines11, 12 and 14). In line 18, Jan tries again and produces another first part of the ritual "how are you" sequence wie geth's? (how are you) (line 18). This time Max responds to Jan's inquiry and continues talking about his life in America (lines 19-20). Max understands Jan's first part of the "how are you" as an inquiry about his stay in America. Max's response to the "how are you” in this German telephone conversation opening is topicalized. The relevant lines are marked with arrows.

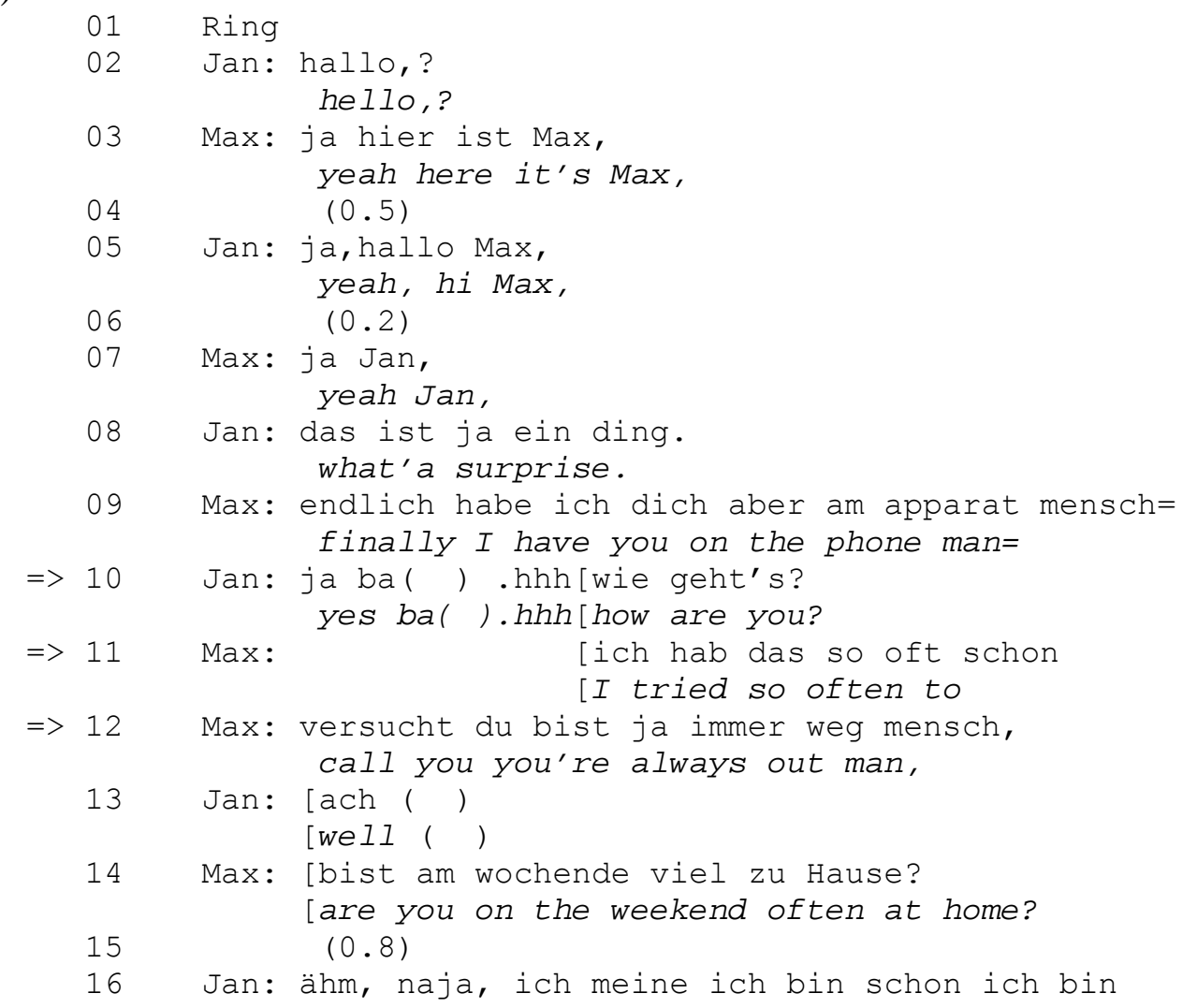




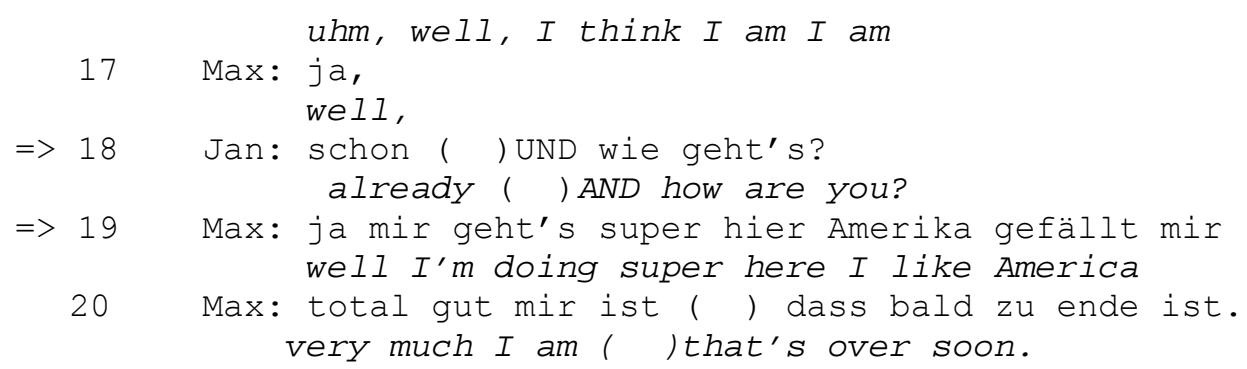

According to Sacks (19671992: 555) the "how are you” sequences provide an early opportunity for the co-participants who receive the first part of the "how are you" sequence to talk about some matters which might be of joint priority concern. In my German data corpus, the German co-participants may produce only the first part of the "how are you" sequence, which is used by the "how are you" receiver as an opportunity to introduce the first topic. However, this does not occur often. The next example illustrates the occurrence of the ritual "how are you" sequence in a conversation between two friends. Note that unlike the ritual "how are you" sequences in the Iranian telephone conversation openings, the "how are you" in this phone conversation is not expanded into the inquiries about each other's family. The second part to the reciprocated "how are you" sequence is developed into a topic (line 10).

Karin calls her friend Dagmar after a long time. Both parties exchange a set of ritual "how are you" sequences (lines 7-10). According to Schegloff (1986: 129), “positive” and "negative" responses to ritual inquiry may engage in talk on that topic. In this segment, after responding positively, Karin continues talking about herself and what she has been doing (line 10).

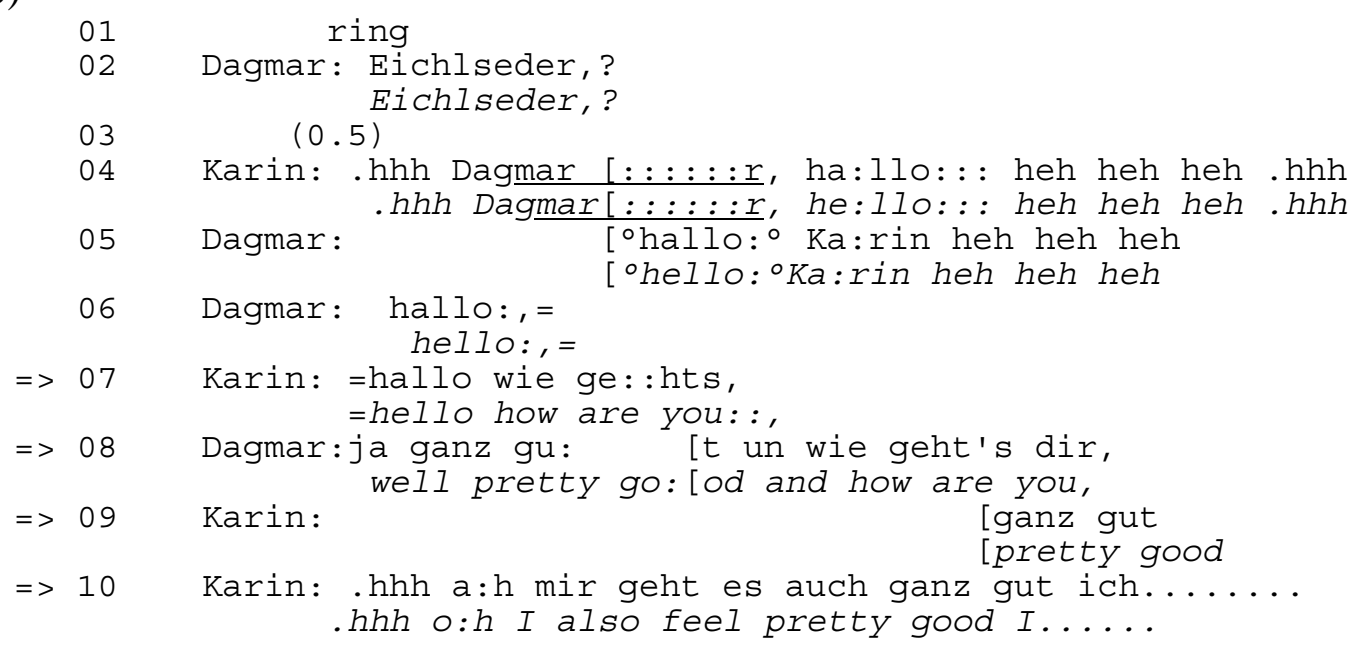

In short, the German telephone conversation opening data suggest that Germans frequently perform no exchanges of "how are yous." In other words, after identification and recognition have been achieved, speakers frequently exchange a set of greetings that is then followed by talking about the reason for the call or some other topic. Further, it was 
illustrated that if the "how are you" sequence is produced, it is regularly produced by one party. That is, the "how are you" sequences in the German telephone conversation openings are frequently not reciprocal. Finally, it was demonstrated that Germans may perform two sets of the ritual "how are you" sequences, however, this occurs relatively seldom in my German data corpus.

\section{Pragmatic interference in native-nonnative telephone conversation opening}

Recent studies of cross-cultural pragmatics have produced important empirical findings, primarily through the identification and comparison of linguistic patterns and speech acts in diverse languages (Thomas 1984; Blum-Kulka, House, and Kasper 1989; Vollmer and Olshtain 1989; Kasper 1992; Eslamirasekh 1993; Saito and Beecken, 1993; Kasper and Blum-Kulka 1993; Jaworski 1994; Nelson, G., and Al-Batal, M. \& Echols, E. 1996; Trosborg, 1995). In general, they have illustrated some culture specific differences in the ways certain speech acts are carried out in different cultures. A number of these crosscultural studies have explored how those features are developed and used by nonnative speakers. These researchers have concentrated on "pragmatic transfer', i.e. the impact of the speaker's native language on their speech act knowledge and performance of speech acts in the foreign language. By investigating native-nonnative speaker conversational interactions, researchers have tried to understand the sources of failure to understand a speaker's intention and miscommunication. (Thomas 1984; Kasper and Blum-Kulka 1993; Saito and Beecken 1993, Jaworski 1994, and Trosborg 1995).

The above studies on cross-cultural pragmatics have conducted their research with respect to speech act theory, and thus have based their analyses on elicited data corpora such as interviews, native intuitions, questionnaires or discourse completion questionnaires. Yet in studying cross-cultural pragmatics, we are investigating the relationship between interaction, culture and context in encounters between native and nonnative speakers. One cannot capture the interpersonal situation and the context in which pragmatic transfer and miscommunication occur when analyzing isolated sentences. In other words, how can we know whether the nonnative speaker's intention was understood by the native speaker or the person being addressed when their data are not included in the study? Therefore, for a better understanding of how transfer of specific native language norms to the target language influences the interaction between native and nonnative speakers and how speakers orient to it in their talk, we need to explore naturally occurring conversations.

This concern of using the appropriate methodology for the analysis of native and nonnative interaction has also been discussed by other scholars (Moerman, 1996; Wagner, 1996; Seedhouse, 1998, and Wagner, 1998). Moerman (1996: 156) and Seedhouse (1996: 85) suggest Conversation Analysis (CA) as the appropriate method for investigation of "foreign language interaction". According to Seedhouse, CA is the most "tenable methodology" for the analysis of naturally occurring conversation, since it reveals the interactional orientations of the interactants in context, together with the structural organization of their interaction, through analyzing the details of the conversation (1998: 101). For this reason, I have adopted Conversation Analysis (CA) as the methodology to conduct my cross-cultural research on everyday conversation. 
The focus of the last section of this paper is on the interaction between native and nonnative speakers on the telephone. Specifically, the interactional function of the ritual "how are you" sequences will be illustrated in telephone conversations between German native speakers and Iranian nonnative speakers of German. Further, this section will analyze how the cultural differences in the way German and Iranian co-participants go through the telephone conversation openings routines can interfere with the co-participant's intention and understanding of the activity.

\subsection{The "how are you" exchanges in the native-nonnative telephone conversation opening}

So far, I have contrasted telephone conversation openings in Iran and Germany and demonstrated how members of each culture have different norms for this particular social activity. The analysis of the Iranian and German telephone conversation openings demonstrated that German co-participants frequently perform no exchanges of "how are yous". They may perform one sequence of the ritual "how are you" which is usually not reciprocal. Unlike the German co-participants, Iranians ordinarily perform the ritual reciprocated "how are you" sequence. Further, it was illustrated that Iranians usually expand the ritual "how are you" sequence by not only inquiring about each other's well-being but also about the well-being of their family members. The focus of the last section of this paper is on the interaction between native and nonnative speakers on the telephone. Specifically, the interactional function of the ritual "how are you" sequences will be illustrated in telephone conversations between German native speakers and Iranian nonnative speakers of German. Further, this section will analyze how the cultural differences in the way German and Iranian co-participants go through the telephone conversation openings routines can interfere with the co-participant's intention and understanding of the activity.

The next data excerpt (11) will illustrate how the cultural difference in the ritual "how are you” exchanges in the Iranian culture is transferred by an Iranian nonnative speaker of German when conversing in German with German native speakers. This is a telephone conversation between two relatives, a German native speaker (Jessi) and a nonnative speaker of German (Kami) who has lived many years in Germany and is fluent in German. In this conversation, the nonnative speaker (the caller) inquires twice about the German native speaker's well-being (lines 10 and 20) before inquiring about her husband's well-being (Norbert) (lines 23 and 26). And finally, he inquires about the well-being of Jessi's children, Anja and Laura (line 45). In addition to the elaborated inquiry moves, another culturally contrasting feature of this example is the intrusion of pauses after the nonnative speaker utters the "inquiry." Note that in the Iranian telephone openings, the exchanges of "how are yous” occur frequently in overlap with no pauses, whereas in this segment of nativenonnative speaker, Kami's inquiries about Jessi's, her husband's, and her children's well-being are followed by pauses (lines 11, 24, and 46). Further, note that Kami's inquiry about Jessi's husband's well-being (lines 22 and 23) is followed by Jessi's repair initiation ha? (huh?) (line 25). This occurs after a pause (line 24). Jessi's repair initiation signals breakdown in hearing or understanding of the previous turn(Schegloff, Jefferson and Sacks 1977), which is Kami’s inquiry about her husband's well-being. It seems that Kami's inquiries are not 
expected by Jessi since these ritual inquiries are not the norms in German telephone conversation openings.

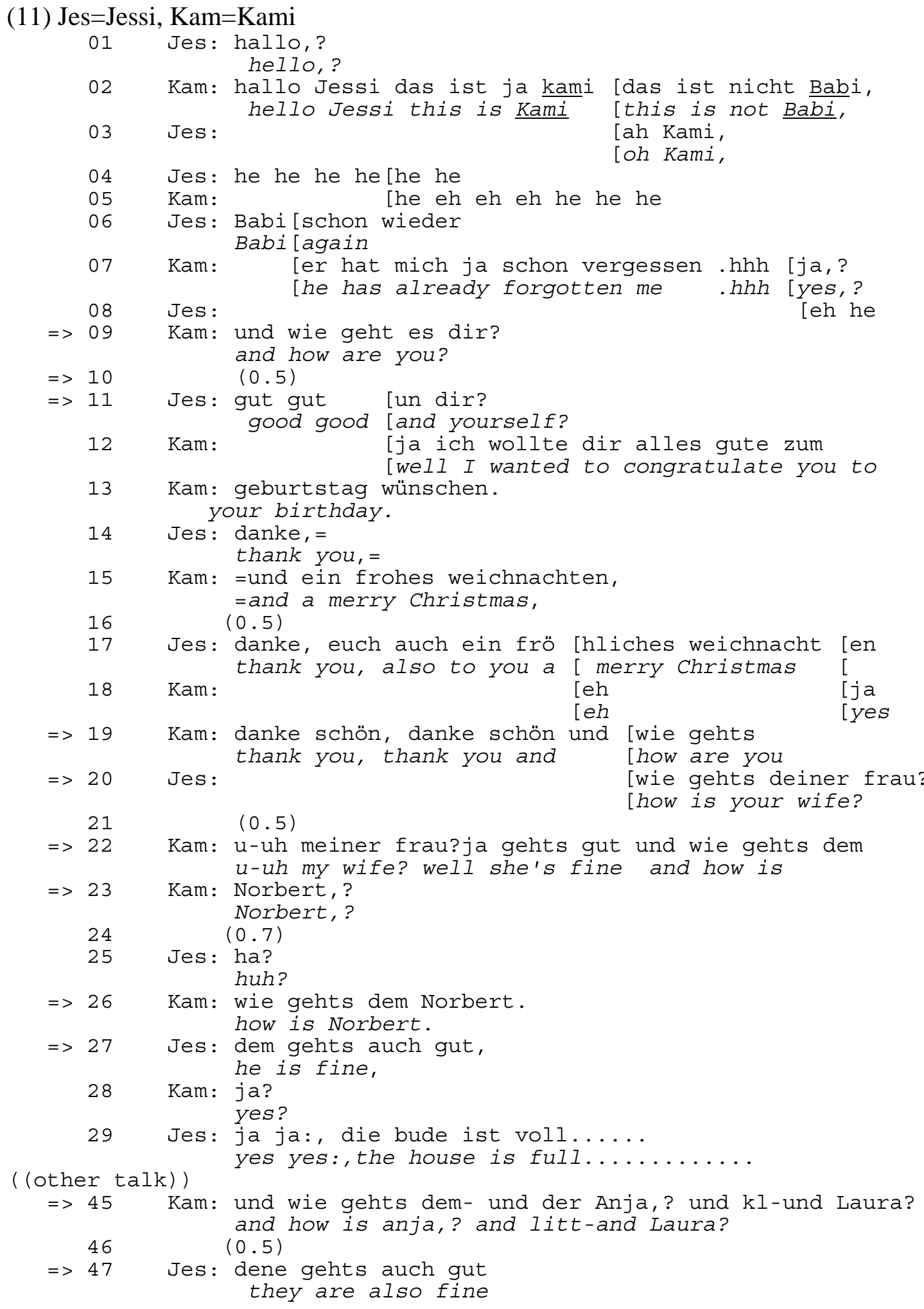


Sacks (1964-65/1992: 40) notes that members of the population can be classified into categories such as sex, age, race, religion, etc. Further, he explains that these categories are "inference rich", i.e. that there is a set of inferences attached to each category that is “common knowledge" (Sacks, 1964-65/1992: 40 and 69). In other words, the majority of activities produced and understood by the members of a society are handled in terms of the categories they are "bound" to (Sacks, 1964-65/1992: 179). In the case of telephone conversation openings between native and nonnative speakers, we are dealing with two different categories, namely German native speakers and Iranian native speakers. Each member of these categories has a "common knowledge" about the norms of different social activities, for example opening and closings of conversation, making a request, etc. Thus, when engaging in an activity, each member behaves according to the norms that are bound to the activity.

In the above data excerpt, the Iranian nonnative speaker goes through the norms of telephone conversation openings common in his culture. In other words, as a member of the Iranian culture category, he produces the expanded ritual "how are you" sequences that are bound to Iranian culture even though the conversation is in German. It seems that people who come from cultures in which such routinized formulae are part of their habitual speech are unlikely to discard that pattern when they acquire a foreign language. Unlike the Iranian and German telephone conversation openings in which the opening sequences were frequently produced in overlaps, the opening sequences in telephone conversations between native and nonnative speakers include many pauses. These pauses occur mainly after the first part of the ritual inquiries are produced. The pragmatic transfer of the ritual inquiries may impede the conversation in that this telephone conversation opening is not carried out as smoothly as were the native speaker ones. Further, such transfer may lead to repair initiation and thus breakdown in the understanding of the conversation.

Frequently, in the native-nonnative speaker's telephone conversation data corpus, the responses to the Iranian nonnative speakers' ritual "how are yous" are topicalized by the native speakers of German. In other words, ritual inquiries about the German native speaker's well-being are frequently developed into a topic. As was illustrated in the Iranian telephone conversation openings, Iranian responses to the first ritual inquiries about each other's well-being are rather short. Only after several inquiries about one another's and their family's well-being will Iranian co-participants talk about the reason for the call, or move on to other topics.

The analysis of native-nonnative speaker data suggests that the transfer of automated routinized formulae common in Persian can lead to a mixture of ritual and topical talk. That is, when nonnative speakers of German produce a series of ritual inquiries when conversing in German with a German native speaker on the telephone, the ritual inquiries may be understood by the German native speaker as topic elicitation. Segment (12) illustrates such a pragmatic transfer. Mehdi is an Iranian who has lived in Germany for many years and is fluent in German. He calls his friends Ana (a German native speaker) and her husband, who also is an Iranian. After identification and recognition are achieved (lines 1-5) Mehdi produces the first part of the ritual "how are you" (line 6) and receives its second part in line 
7. The initial "how are you" sequence is reciprocated in that Ana also inquires about Mehdi’s well-being (line 11). Usually, when one speaker produces a ritual "how are you", after responding to it the next speaker also inquires about the well-being of that speaker (Schegloff, 1979: 52). In response, Mehdi produces the second part of the "how are you" sequence and inquires about Ana's son's well-being (line 13). Ana’s response about Ramin's state of health is developed into a topic (lines 14- 52). After having talked about this topic for a while, Mehdi produces another ritual inquiry of "how are you", this time he inquires about the health of Ana's parents (line 57). This is developed into another topic (not included in the transcript).

(12) Meh=Mehdi






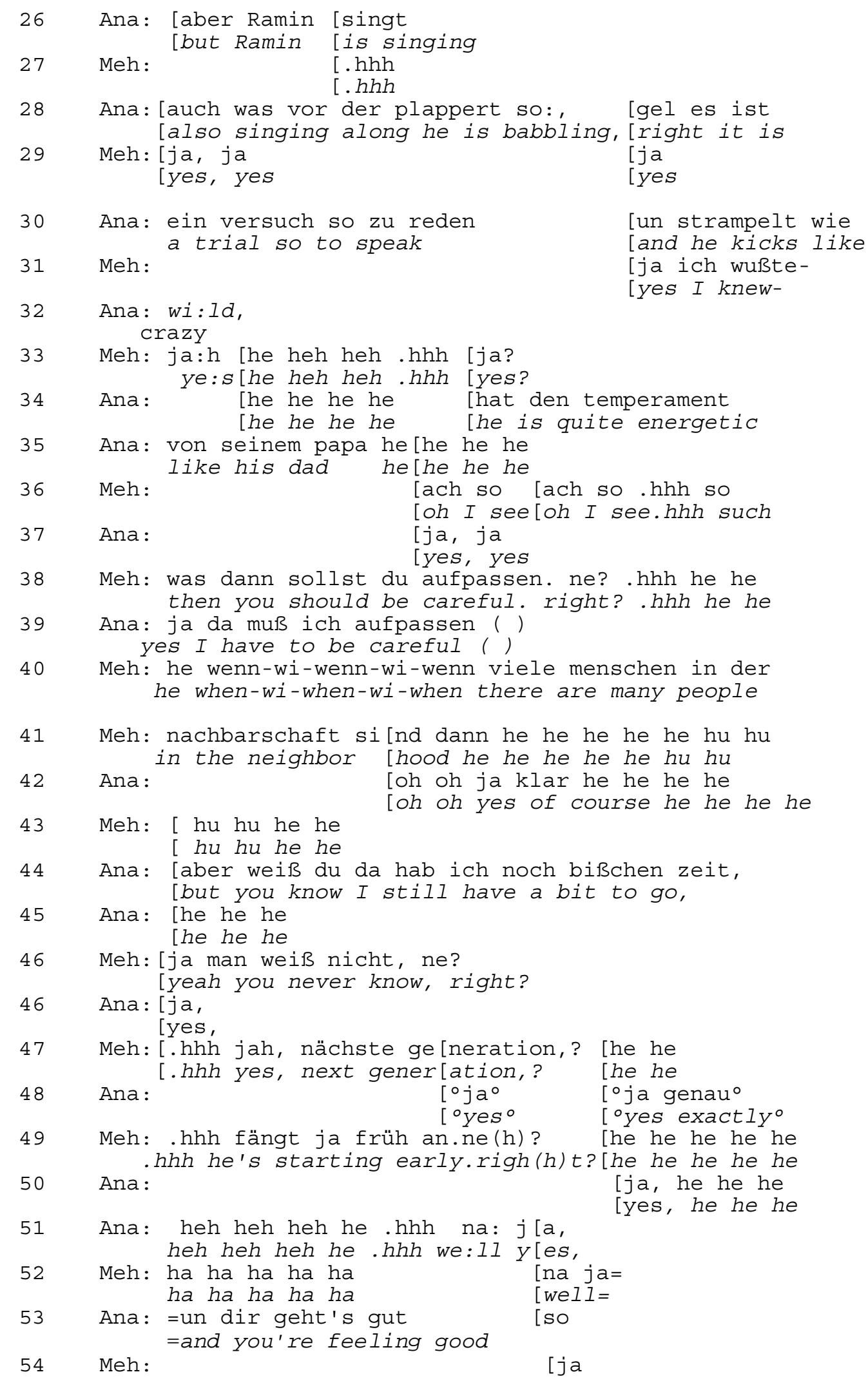




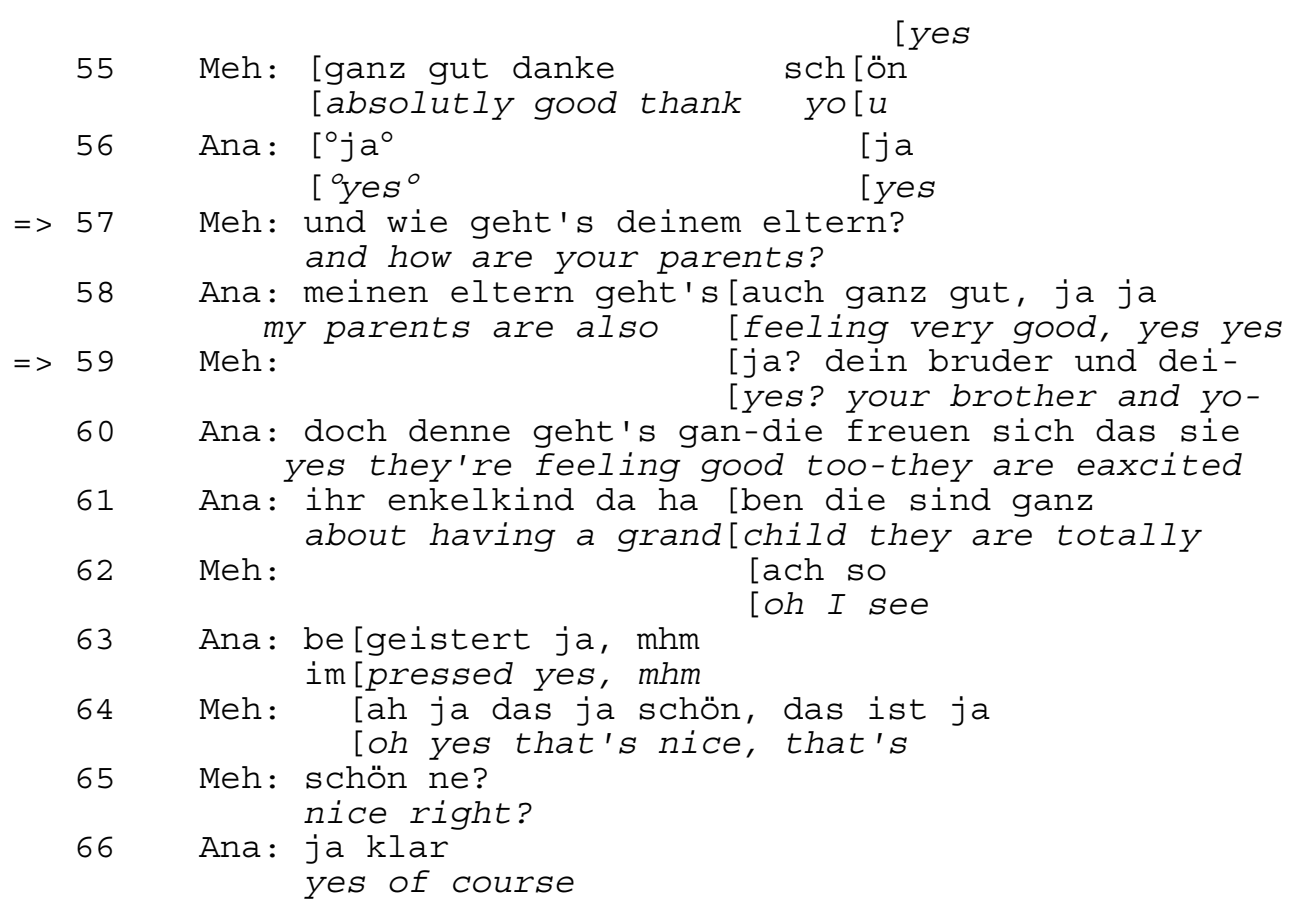

The culturally distinctive feature of this telephone conversation opening is the expansion of the turns between the "how are you" sequences. It was illustrated earlier how, in the Persian telephone conversation openings, the "how are you" sequences are performed one after the other, frequently in overlap. Only after several "how are yous" are exchanged is the first topic introduced. It was also demonstrated that in my German data, the response to the first part of the "how are you" sequence is topicalized. The above data excerpt exemplifies how co-participants, as members of different categories with different expectations and understanding of the context, can act according to the norms of their culture. Thus, such pragmatic transfer may interfere with co-participants' understanding of the action.

\section{Summary}

After contrasting the norms in opening telephone conversations in Iran and Germany, this paper explored the first opening sequences in native and nonnative speaker interaction. The study of native-nonnative speaker telephone conversation openings in this paper suggests two features of pragmatic transfer. First, it was shown that the transfer of routinized ritual inquiries may impede the conversation and lead to breakdown in the understanding of the activity (segment 11). That is, the nonnative speaker's ritual inquiry about the native speaker's and their family's well-being is followed by a pause and a repair initiation. This may be due to the fact that German native speakers' expectations and understanding of the norms of the activity may be different than their Iranian co-participants'. Secondly, it was illustrated how the ritual inquiries about the co-participant's and their family's status may be treated by the German native speakers as topical inquiries (segment 12).

Coulmas describes conversational routines as a set of tools which individuals employ in order to relate to others in an accepted way (1981:2). For Iranian speakers, an accepted 
way to open an encounter on the telephone is to perform several ritual inquiries. The pragmatic transfer discussed in this paper occurs even though these nonnative speakers have been living in Germany for several years and are quite familiar with German language and culture. One important reason for pragmatic transfer seems to be that most Iranian speakers of German are not really consciously aware of the conversational routines in their native language and in the target language. In acquiring one's native language, one also learns the norms of interacting in the native culture. When nonnative speakers converse in another language, they frequently tend to behave according to the socioculturally appropriate norms of their native language rather than those of the target language, often regardless of their level of proficiency (Eisenstein and Bodman, 1993: 75). It seems that Iranian speakers of German apply the socially appropriate ritual formulae from their native language to German telephone conversation openings. This may be because the norms and routines in German telephone conversation openings are very different from the routines and culturally acceptable norms of speech behavior in telephone conversation openings in Iran. As a result of such pragmatic transfer, misinterpretation of the intent of the action is possible.

\section{Appendix: Transcription notations}

All telephone conversation data were transcribed according to the transcription notation developed by Gail Jefferson (1984: viv-xvi). The following symbols were used in the transcripts:

$\begin{array}{ll}\cdot & \text { A period indicates a fall in tone. } \\ ? & \text { A comma indicates continuing intonation. } \\ \text { ?, } & \text { A question mark indicates rising intonation. } \\ \text { A question mark and a comma indicate rising intonation weaker than that } \\ \text { indicated by a question mark. } \\ \text { A colon indicates an extension of the sound or syllable it follows } \\ \text { (co:lon). } \\ \text { More colons (co:::lon) prolong the stretch. } \\ -: & \text { A single dash indicates an abrupt ending or a cutoff. } \\ \text { mine } & \text { Emphasis is indicated by underlining. } \\ \text { CAP } & \text { Capital letters are used to indicate an utterance, or part thereof, } \\ & \text { that is spoken much louder than the surrounding talk. } \\ & \text { A degree sign is used to indicate a passage of talk which is quieter } \\ \text { than the surrounding talk. } & \text { Audible aspirations } \\ \text { (hhh) } & \text { Audible inhalations } \\ \text { hhh } & \text { Vocalizations that are not recognizably, i.e. the transcription is not } \\ ((\quad)) & \text { clear. } \\ >\text { mine }< & \text { Part of an utterance is delivered at a pace quicker than the surrounding talk. } \\ (\quad \text { ) } & \text { Items in doubt are enclosed within single parentheses. } \\ \text { [I used } & \text { Utterances starting simultaneously are linked together with left- } \\ \text { [I saw } & \text { hand brackets. } \\ \text { I us[ed to } & \text { When overlapping utterances do not start simultaneously, left-hand }\end{array}$




[he is $\quad \begin{aligned} & \text { brackets are used to mark the point at which an ongoing utterance } \\ & \text { is joined. } \\ & \text { Utterances are linked together with equal signs, when utterances } \\ & \text { are latched immediately (no interval between adjacent utterances). }\end{aligned}$
$\begin{aligned} & \text { Intervals in the stream of talk are timed in tenths of a second and inserted } \\ & \text { within parentheses, either within an utterance or between utterances. }\end{aligned}$

\section{References:}

Beeman, W. (1986) Language, Status, and Power in Iran. Bloomington: Indiana University Press.

Beeman, W. (1976) Status, style and strategy in Iranian interaction. Anthropological Linguistics 18: 305-322.

Blum-Kulka, S., House, J. \& Kasper, G. (1989) Cross-cultural pragmatics: Request and apologies. Norwood, NJ: Ablex.

Brinker, K. and Sager, S. F. (1989) Linguistische Gesprächsanalyse: Eine Einhührung. Berlin: Erich Schmidt Verlag.

Brown, P. \& Levinson, S. (1987) Politeness: Some universals in language usage. Cambridge: Cambridge University Press.

Coulmas, F. (1979) On the sociolinguistics relevance of routine formulae. Journal of Pragmatics 3: 239-266.

Coulmas, F. (1981) Conversational routines: Exploration in standardized communication situations and prepatterend speech. New York: Mouton Publishers.

Ellis, R. (1994). The study of second language acquisition. New York: Oxford University Press.

Godard, D. (1977) Same setting, different norms: Phone call beginnings in France and the United States. Language in Society 6: 209-19.

Hillmann, M. C. (1978) Language and social distinctions in Iran. In M. E. Bonine and N. R. Keddie (eds.), Modern Iran: The dialectics of continuity and change. Albany: State University of New York Press.

Hodge, C. T. (1957) Some aspects of Persian style. Language 33: 355-69.

Hopper, R. and Chen, Chia-Hui (1996) Languages, cultures, relationships: Telephone openings in Taiwan. Research on Language and Social Interaction 29(4): 291-313.

Houtkoop-Steenstra, H. (1991) Opening sequences in Dutch telephone conversations. In Deirdre Boden \&Don Zimmerman (eds.), Talk and social structure. Berkeley: Unviersity of Califormia Press.

Jaworski, A. (1994) Pragmatic failure in a second language: Greeting responses in English by Polish students. IRAL 32(1): 41-55.

Jefferson, G. (1984) Transcript on notation. In J.M. Atkinson \& J. Heritage (eds.), Structures of social action. Cambridge: Cambridge University Press, ix-xvi.

Kasper, G. (1992) Pragmatic transfer. Second Language Research 8: 203-231.

Kasper, G. and Blum-Kulka, S. (1993) Interlanguage Pragmatics. New York: Oxford University Press. 
Liefländer-Koistinen, Luise and Dagmar Neuendorf. (1991). Auskuft erbitten.

Telefongespräche im Deutschen und Finnischen: Unterschiede in ihrer interaktionalen Struktur. Akten des VIII. Internationalen Germanisten Kongresses, Tokyo 1990, vol 3 München: Indicium. 4: 482-494

Lindström, A. (1990) Identification and recognition in Swedish telephone conversation openings. Language in Society 23: 231-252.

Moosavie, S. M. (1986) A sociolinguistic analysis of the Persian system of taarof and its implication for the teaching of Farsi. Ph.D. dissertation, University of Texas at Austin.

Pavlidou, T. (1994) Contrasting German-Greek politeness and the consequences. Journal of Pragmatics 21: 487-511.

Sacks, H. $(1964,1992)$ Rules on conversational sequence. In G. Jefferson (ed.), Lectures on Conversation. Cambridge: Blackwell.

Sacks, H., Schegloff, E. A. \& Jefferson, G. (1974) A Simplest systematics for the organization of turn-taking for conversation. Language 50: 696-743.

Schegloff, E. A. (1972) Sequencing in conversational openings. In John J. Gumperz and Dell Hymes (eds.), Directions in Sociolinguistics: The ethnography of communication. New York. Holt, Rinehart and Winston, Inc. 346-380.

Schegloff, E. A. (1979). Identification and Recognition in Telephone Conversation Openings. In George Psathas (ed.), Everyday language: Studies in ethnomethodology. New York. Irvington publisher, 23-78.

Schegloff, E. A. (1986) The routine as achievement. Human Studies 9:111-151.

Schieffelin, B. B. \& Ochs, E. (1986) Language socialization across cultures. Cambridge: Cambridge University Press.

Sifianou, M. (1989) On the telephone again! Differences in telephone behaviour: England versus Greece. Language in Society 18:527-44.

Tannen, D. and Cömert, P. C. (1981). "Health to you Mouths: Formulaic Expressions in Turkish and Greek." In F. Coulmas (ed.), Conversational routine: Explorations in standardized communication situations and prepatterened speech, 37-54.

Thomas, J. (1983) Cross-cultural pragmatic failure. Applied-Linguistics 4 (2): 91-112.

Werlen, Iwar. (1984) Ritual und Sprache. Zum Verhältnis von Srpechern und Handeln in Ritualen. Tübingen: Narr. 